\title{
Saldos dos repasses federais no SUS: o que temos e o que esperar do incremento para a COVID-19
}

\author{
Balances of federal transfers in SUS: what we have \\ and what to expect from the COVID-19 increment
}

Daniel Resende Faleiros (https://orcid.org/0000-0003-2576-5360) ${ }^{1}$

Blenda Leite Saturnino Pereira (https://orcid.org/0000-0002-7831-0258) ${ }^{2}$

\footnotetext{
${ }^{1}$ Faculdade de Farmácia, Universidade de Federal de Minas Gerais. Av. Pres. Antônio Carlos 6627, São Luiz. 31270-901 Belo Horizonte MG Brasil. dfalleiros@gmail.com ${ }^{2}$ Programa de PósGraduação em Saúde Pública, Faculdade de Saúde Pública, Universidade de São Paulo. São Paulo SP Brasil.
}

\begin{abstract}
We analyzed the balances from the transfers from the Ministry of Health $(\mathrm{MH})$ to subnational entities, to finance the Unified Health System (SUS), including for COVID-19. We verified the representativeness of these in relation to the transfers from the $\mathrm{MH}$ to public health actions and services, between 2019and 2020. We analyzed the $M H$ ordinances that gave rise to the COVID-19 transfers, classifying them as: quantity; object; apportionment criterion; amount of installments; execution linked to MH strategies; value. More than 70.000 current accounts were accounted for, and some subnational entities had more than 100. In 2019, balances reached $R \$ 16.29$ billion (annual increase of $10.2 \%$ ), representing $19.9 \%$ of the total transferred. In 2020, they reached $R \$ 23.83$ billion (an increase of $46.3 \%$ ), representing $21.1 \%$ of all transfers, with a monthly trend of continued growth. More than 616 ordinances, with 28 different objectives, transferred $R \$ 32.30$ billion to COVID-19. The resource, originally freely available, had $R \$ 11.88$ billion (36.8\%) linked to the strategies of the $M H: R \$ 1.36$ billion (99.9\%) linked to the Structuring Block, and $R \$ 10.52$ billion (34.0\%) linked to the Maintenance Block. There are several causes that give rise to the accumulation of balances, however the quality, quantity and complexity of the SUS normative framework strongly contribute to an execution of resources that is not very fast, effective, efficient and useful.
\end{abstract}

Key words Public health, Health economic, Budgets
Resumo Analisamos os saldos provenientes dos repasses do Ministério da Saúde (MS) aos entes subnacionais, destinados ao financiamento do Sistema Único de Saúde (SUS), inclusive para COVID-19. Verificamos a representatividade destes frente aos repasses do MS destinados às ações e serviços públicos de saúde, entre 2019 e 2020. Analisamos as portarias do MS que deram origem aos repasses COVID-19, classificando-as em: quantidade, objeto, critério de rateio, quantidade de parcelas, execução vinculada a estratégias do MS, valor. Mais de 70 mil contas-correntes foram contabilizadas, alguns entes subnacionais tinham mais de cem. Em 2019, saldos atingiram $R \$ 16,29$ bilhões (aumento anual de 10,2\%), representando 19,9\% do total repassado. Em 2020, $R \$ 23,83$ bilhões (aumento de $46,3 \%$ ), representando $21,1 \%$ do repassado, com tendência de crescimento. Mais de 616 portarias, com 28 diferentes objetivos, repassaram $R \$ 32,30$ bilhões à COVID-19. O recurso, antes de livre utilização, teve $R \$ 11,88$ bilhões (36,8\%) vinculados às estratégias do MS: R\$1,36 bilhão (99,9\%) Bloco Estruturação e R\$10,52 bilhões (34,0\%) Bloco Manutenção. Várias podem ser as causas que dão origem ao acúmulo de saldos, todavia qualidade, quantidade e complexidade do arcabouço normativo do SUS contribuem fortemente para uma execução dos recursos pouco célere, efetiva, eficiente e eficaz.

Palavras-chave Saúde pública, Economia da saúde, Orçamentos 


\section{Introdução}

Com a promulgação da Constituição Federal ${ }^{1}$ em 1988, o direito à saúde foi assegurado a toda população do Brasil. Para atender tal determinação foi criado o Sistema Único de Saúde (SUS), tendo como princípios basilares a universalidade, a integralidade da atenção e a promoção da equi$\mathrm{dade}^{2}$. Do ponto de vista das relações financeiras intergovernamentais, a criação do SUS materializou-se por meio de um esquema tripartite de financiamento, integrando recursos da União dos Estados, Distrito Federal e Municípios ${ }^{3}$. Todavia, apenas em 2000 a Emenda Constitucional $n^{\circ} 29^{4}$ disciplinou as responsabilidades do financiamento e somente em 2012 a Lei Complemen$\operatorname{tar} n^{\circ} 141^{5}$ definiu quais são as despesas consideradas com Ações e Serviços Públicos de Saúde (ASPS), além de regulamentar as transferências regulares e automáticas dos recursos federais aos entes subnacionais ${ }^{6}$. Nos últimos dez anos, a composição de despesas do SUS tem sido, em média: 43\% sob responsabilidade da União, 26\% dos Estados e 31\% dos Municípios 7 .

No tocante à aplicação dos recursos federais, as transferências aos entes subnacionais ocupam posição de destaque na execução orçamentária do Ministério da Saúde (MS), destinando o maior volume de recursos para a manutenção das ASPS O MS realiza as transferências do Fundo Nacional de Saúde (FNS) para os Fundos de Saúde dos entes subnacionais, considerando uma série de normas e princípios orçamentários pertinentes à administração pública, bem como um conjunto de normas e pactuações no âmbito do SUS, que dentre outras imputam aos gestores subnacionais obrigações e coíbem atos que visam fins diversos dos previstos ${ }^{8,9}$. Em 2019, a União registrou uma despesa total de R $\$ 122,3$ bilhões com ASPS, sendo $69 \%$ repassados aos entes subnacionais para Estruturação (2,0\%) e Manutenção $(98,0 \%)^{10}$. Contudo, dados do MS registram, em dezembro de 2019, um valor de $\mathrm{R} \$ 16,3$ bilhões em saldos nas contas-correntes destes repasses. Estes saldos representam a diferença entre o volume de recursos transferidos e as despesas efetivamente pagas em um determinado período, fenômeno denominado "empoçamento de despesas". Muitas podem ser as causas do grande volume de recursos empoçados, entretanto no entendimento da Secretaria do Tesouro Nacional do Brasil uma das principais razões é o excesso de vinculações de receitas e despesas, principalmente nas áreas da Saúde, Defesa e Educação ${ }^{11}$.

No ano de 2020, o orçamento do MS que contabilizava $\mathrm{R} \$ 124,20$ bilhões destinados à execução de ASPS recebeu um incremento de $\mathrm{R} \$ 64,12$ bilhões em créditos extraordinários ${ }^{12}$, direcionados ao FNS. Diferentemente dos créditos ordinários, tais recursos adicionais não constavam na Lei de Orçamentaria Anual e somente foram autorizados em função do reconhecimento do estado de calamidade pública instalado no Brasil $^{13}$, decorrente da pandemia do novo Coronavírus. Estes recursos extraordinários foram disponibilizados para o financiamento de ASPS, exclusivamente dedicadas ao enfrentamento da COVID-19, alocados para a execução direta do MS, transferências ao exterior, a filantrópicos e a Estados, Distrito Federal e Municípios, o que ampliou os volumes de saldos.

A fim de viabilizar a utilização dos recursos empoçados, inclusive para ações de enfrentamento da COVID-19, foi promulgada a Lei Complementar $n^{\circ} 172 / 2020^{14}$ que possibilitou a execução dos saldos remanescentes no período de calamidade. Todavia, ainda em 2020, o volume de saldos chegou a atingir R $\$ 31,73$ bilhões ${ }^{15}$. Neste contexto, o presente estudo apresenta contribuições inéditas quanto a investigações sobre legalidade, transparência e vinculação de recursos direcionados ao SUS, que devem ser executados em observância a preceitos de autonomia e eficiência administrativa.

\section{Objetivo}

Analisar os saldos financeiros provenientes dos repasses do MS aos entes subnacionais, no âmbito do financiamento do SUS, entre os anos de 2019 e 2020, incluindo recursos destinados ao enfrentamento da COVID-19, apontando possíveis causas deste fenômeno.

\section{Materiais e métodos}

\section{Desenho do estudo}

Trata-se de uma análise descritiva que tem como objeto a evolução do volume de saldos financeiros relativos aos repasses federais no SUS, correlacionando-os de forma argumentativa, com o arcabouço normativo do financiamento do sistema. Tais repasses são destinados ao financiamento de ASPS e ocorrem em contas de depósito à vista (contas-correntes), abertas pelo FNS ${ }^{10}$ em instituições financeiras federais - Banco do Brasil e Caixa Econômica Federal - restando sob a gestão dos entes subnacionais.

A fim de alcançar o objetivo do estudo foram verificados, mensalmente, durante os anos 
de 2019 e 2020, para Estados, Distrito Federal e Municípios, os valores totais destes repasses e dos saldos remanescentes. Foram ainda verificadas a representatividade dos saldos frente aos repasses ocorridos; a quantidade e evolução do número de contas-correntes, e; os valores dos saldos. Com utilização de Microsoft Excel ${ }^{\circledR}$ e tendo como base os valores de saldos de janeiro de 2019 a março de 2020, foi calculada a curva de tendência da evolução dos saldos de abril de 2020 a janeiro de 2021. Assim, foi possível verificar e comparar a dinâmica do empoçamento pré-pandemia e em 2020.

Com o intuito de conhecer e verificar possíveis desdobramentos em virtude do aporte de recursos à COVID-19, as normas que deram origem aos repasses do MS (Portarias) foram classificadas segundo: 1) Bloco de repasses que permite conhecer o tipo de despesa para as quais os recursos foram repassados, se para ações de estruturação ou de manutenção; 2) Quantidade de Portarias que deram origem aos repasses, que permite conhecer o volume de normativas com as quais os gestores tiveram de lidar durante a pandemia; 3) Objeto de cada Portaria que possibilita conhecer qual a destinação dos recursos repassados apontando se é de uso geral ou se vincula a alguma estratégia específica do MS; 4) Forma de rateio do recurso que apresenta o critério utilizado para a distribuição dos valores e permite conhecer a complexidade das normativas com as quais os gestores tiveram de lidar durante a pandemia; 5) Frequência de parcelas dos repasses, destinada a conhecer se os repasses seriam em parcela única ou divididos, indicando a complexidade de planejamento e execução dos recursos recepcionados; 6) Tipo de vinculações para a utilização dos recursos, destinado a contabilizar o volume de normas que vinculam a execução dos recursos, para além da vinculação legal do programa de trabalho, às estratégias específicas do MS, e; 7) Valor total anual dos repasses. Tal análise descritiva foi realizada para organizar, resumir e descrever os aspectos mais importantes deste conjunto de características observadas.

\section{Fontes de dados}

Os dados utilizados neste estudo foram coletados nos sistemas informatizados do Governo Federal. Dados relativos ao orçamento do MS foram extraídos do Sistema Integrado de Planejamento e Orçamento (SIOP) ${ }^{12}$ que suporta os processos de Planejamento e Orçamento do Governo Federal. Os dados relativos às contas-correntes e valores de saldos financeiros foram extraídos do Portal Loca- liza SUS/MS ${ }^{15}$, plataforma digital do MS, com atualização diária, que reúne painéis eletrônicos que apresentam informações sobre o enfrentamento da COVID-19. Os dados relativos às transferências financeiras, com informações sobre quantidades de contas-correntes e valores dos saldos, tiveram como fonte primária o Fundo Nacional de Saúde. Dados relativos aos valores de repasses para COVID-19 foram extraídos do $\mathrm{FNS}^{10}$, gestor dos recursos do MS, responsável por desenvolver mecanismos que disponibilizem informações à sociedade relativas aos repasses no âmbito do SUS. Todos os parâmetros de consultas e suas respectivas fontes foram descritos no Quadro 1.

\section{Resultados}

\section{Contas-correntes}

Em 2020, o número total de contas-correntes dos Estados, recebedoras apenas dos repasses federais, foi de 1.271 e dos Municípios 70.037. Individualmente, o estado do Pará e os municípios de João Pessoa/PB, São Paulo/SP e Teresina/PI registaram mais de cem contas.

\section{Saldos}

Entre os meses de janeiro/2019 e março/2020, registrou-se certa estabilidade de crescimento, quando a partir de então, em função do aporte dos repasses destinados ao enfrentamento $\mathrm{CO}$ VID-19, ocorreu um significativo aumento. Nos 12 meses de 2019 houve um aumento de $\mathrm{R} \$ 1,51$ bilhão (10,2\%) e em 2020 de R\$ 6,69 bilhões (46,3\%). A projeção dos dados deste cenário registra uma tendência de crescimento $\left(\mathrm{R}^{2}=73,3 \%\right)$. Em dezembro/2019 os R \$16,29 bilhões em saldos representavam $19,9 \%$ do total repassado no ano e em dezembro/2020 os R $\$ 23,83$ bilhões representavam 21,1\% (Gráfico 1).

\section{Recursos ordinários}

Em 2019, o FNS contou com uma dotação orçamentária de $\mathrm{R} \$ 127,19$ bilhões, com previsão de transferências aos entes subnacionais de $\mathrm{R} \$ 82,98$ bilhões $(65,2 \%)$. A execução total foi de $90,6 \%$, sendo $48,6 \%$ dos recursos destinados aos Municípios; 16,7\% aos Estados; 31,1\% de aplicações diretas; e o restante a outras modalidades de aplicação.

Em 2020, a dotação orçamentária foi de R\$184,49 bilhões, com previsão de transferências 
Quadro 1. Materiais e métodos: Fonte de dados.

\begin{tabular}{|c|c|c|}
\hline Dado & \multicolumn{2}{|c|}{ Valores relativos aos orçamentos do Ministério da Saúde } \\
\hline Fonte & \multicolumn{2}{|c|}{ Sistema Integrado de Planejamento e Orçamento - SIOP } \\
\hline Acesso & \multicolumn{2}{|c|}{ https://www.siop.planejamento.gov.br/modulo/login/index.html\#/ } \\
\hline Período & \multicolumn{2}{|l|}{ Anos 2019 e 2020} \\
\hline \multirow[t]{6}{*}{ Consulta } & \multicolumn{2}{|c|}{ Painel do Orçamento Federal } \\
\hline & Órgão orçamentário & $36000 / \mathrm{MS}$ \\
\hline & Unidade Orçamentária & $36211 /$ FNS \\
\hline & $\begin{array}{l}\text { Modalidades de } \\
\text { aplicação }\end{array}$ & $\begin{array}{l}\text { 31; 35; 41; } 45 \text { (Transferências Fundo a Fundo a Estados, Distrito } \\
\text { Federal e Municípios) }\end{array}$ \\
\hline & Valores & Dotação atual (recursos disponibilizados); Empenhado; Pago \\
\hline & Tipos de ações & $\begin{array}{l}\text { Ordinárias; 21C0 Enfrentamento da Emergência de Saúde Pública } \\
\text { de Importância Internacional Decorrente do Coronavírus; 2E89 } \\
\text { Incremento Temporário ao Custeio dos Serviços de Atenção Básica } \\
\text { em Saúde para Cumprimento de Metas; 2E90 Incremento Temporário } \\
\text { ao Custeio dos Serviços de Assistência Hospitalar e Ambulatorial para } \\
\text { Cumprimento de Metas }\end{array}$ \\
\hline Dado & \multicolumn{2}{|c|}{ Valores relativos as contas-correntes e aos saldos } \\
\hline Fonte & \multicolumn{2}{|c|}{ Portal Localiza SUS/MS com bases primárias do FNS } \\
\hline Acesso & \multicolumn{2}{|c|}{ https://localizasus.saude.gov.br/ } \\
\hline Período & \multicolumn{2}{|l|}{ Anos 2019 e 2020} \\
\hline \multirow[t]{4}{*}{ Consulta } & \multirow{4}{*}{$\begin{array}{l}\text { FNS - SALDO } \\
\text { ACOMPANHAMENTO }\end{array}$} & Quantidade de contas \\
\hline & & Valor do saldo em conta \\
\hline & & Esfera de gestão \\
\hline & & Tipo de conta \\
\hline Dado & \multicolumn{2}{|c|}{ Valores de repasses para COVID-19 } \\
\hline Fonte & \multicolumn{2}{|c|}{ Fundo Nacional de Saúde - FNS } \\
\hline Acesso & \multicolumn{2}{|c|}{ https://portalfns.saude.gov.br/consultas/ } \\
\hline Período & \multicolumn{2}{|l|}{ Ano 2020} \\
\hline \multirow[t]{7}{*}{ Consulta } & \multirow[t]{7}{*}{ Repasse do dia } & Ano/Mês \\
\hline & & Repasses \\
\hline & & Blocos \\
\hline & & Grupo CORONAVIRUS (COVID-19) \\
\hline & & Estado/Município \\
\hline & & Instrumento \\
\hline & & Valor \\
\hline
\end{tabular}

Fonte: Elaborado pelos autores.

de $\mathrm{R} \$ 113,57$ bilhões (61,6\%). A execução total foi de $80,8 \%$, sendo $45,4 \%$ destinados aos Municípios; 16,1\% aos Estados; 50,8\% aplicações diretas do MS; e o restante a outras modalidades (Tabela 1).

\section{Recursos extraordinários}

Ao considerar em 2020 apenas os recursos direcionados à COVID-19 (créditos adicionais extraordinários), a dotação orçamentária foi de 


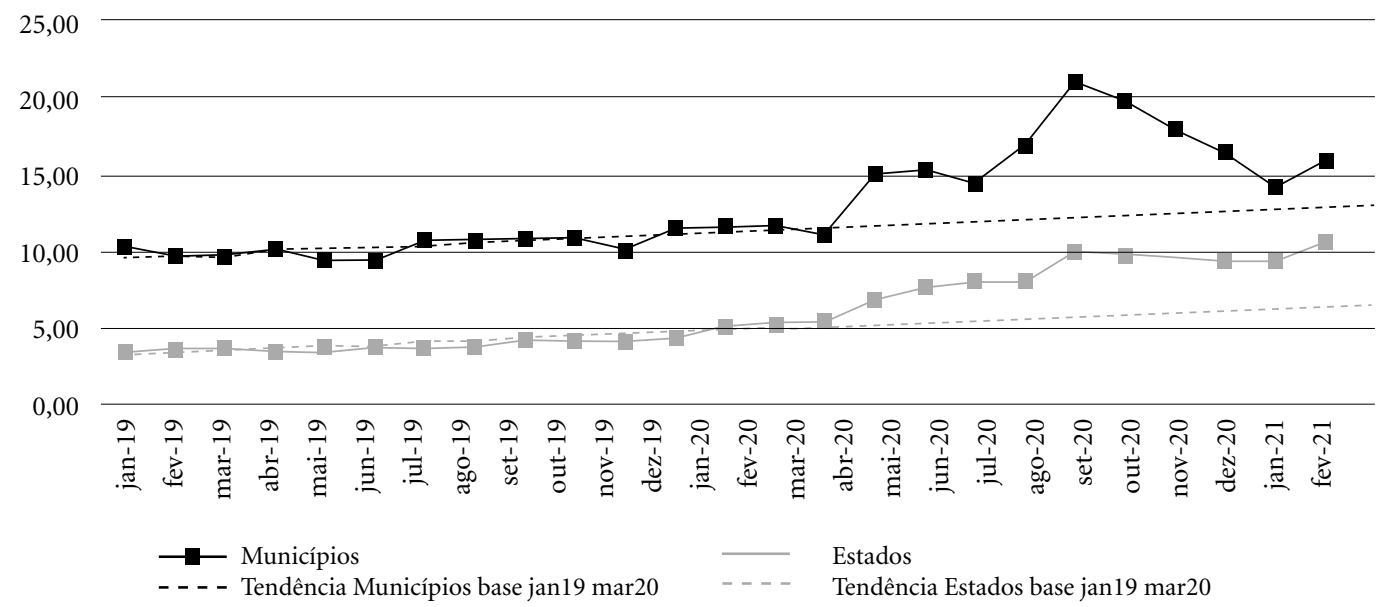

Gráfico 1. Saldos dos repasses FNS - Brasil (R\$ bilhões) (SUS/2019-2020).

Fonte: Localiza SUS. Acesso: Jan/2021.

$\mathrm{R} \$ 64,17$ bilhões, com previsão de repasses aos entes subnacionais de $\mathrm{R} \$ 33,26$ bilhões $(51,8 \%)$. A execução total foi de $61,5 \%$, sendo $36,4 \%$ destinados aos Municípios; 15,4\% aos Estados; 22,8\% aplicações diretas do MS; e o restante a outras modalidades (Tabela 1). As transferências fundo a fundo foram realizadas a partir de março, atingindo o maior volume entre junho/2020 (R \$6,42 bilhões; 20\%) e agosto/2020 (R\$9,12 bilhões; $28 \%$ ). Os repasses foram normatizados por 616 portarias que destinaram recursos para ações de enfrentamento à COVID-19, por meio dos blocos de Estruturação (R \$1,36 bilhões; 4,2\%) e Manutenção (R $\$ 30,93$ bilhões; 95,8\%). Os repasses apresentaram 28 diferentes objetivos, a maioria (21; $75,0 \%)$ realizados em parcela única. Os valores foram classificados em grupamentos significativos. Verificou-se que a maioria dos repasses para Manutenção foi destinada ao custeio das ações e serviços de saúde de maneira geral ( $\mathrm{R} \$ 18,35$ bilhões; $59,3 \%$ ), seguida de repasses direcionados às ações de Média e Alta Complexidade (R \$7,30 bilhões; 23,6\%), Emendas Parlamentares (R \$2,24 bilhões; 7,2\%), Atenção Primária (R \$1,51 bilhão; 5,0\%), Vigilância (R\$857,67 milhões; 2,8\%), Assistência Farmacêutica (R\$649,83 milhões; 2,1\%) e não informados (R \$1,58 milhão). Destes recursos, 34,0\% tiveram a sua utilização atrelada a alguma estratégia do MS, como o Programa Saúde na Escola ou a medicamentos para saúde mental (Tabela 2).
Registra-se que duas outras Portarias publicadas nos últimos dias de dezembro/2020, não foram aqui computadas, visto que os recursos foram transferidos em janeiro/2021. A Portaria 3874/2020 repassou aos Estados, o total de $\mathrm{R} \$ 864,00$ milhões, destinados ao atendimento das demandas assistenciais provocadas pela COVID-19. Por sua vez, a Portaria 3874/2020 repassou aos Municípios o total de R\$143,90 milhões, destinados aos Centros Comunitários de Referência. Ambas em parcela única, por meio do Bloco de Manutenção.

\section{Discussão}

Com uma dotação anual superior a $\mathrm{R} \$ 120,00$ bilhões e execução de 90,0\% o FNS transfere cerca de $65 \%$ dos seus recursos aos entes subnacionais. Todavia, parte destes recursos está empoçado nos Fundos de Saúde de Estados, Distrito Federal e Municípios, com forte tendência de crescimento, visto que saltaram de $\mathrm{R} \$ 13,85$ bilhões no início de 2019, para R \$31,09 bilhões em meados de 2020.

Em 2020, com o advento da COVID-19, ocorreu um aporte federal de $\mathrm{R} \$ 64,17$ bilhões em recursos extraordinários, sendo 51,8\% transferidos aos entes subnacionais. Tal aporte trouxe consigo uma inovação: a finalidade definida no Programa de Trabalho do Orçamento Geral da 


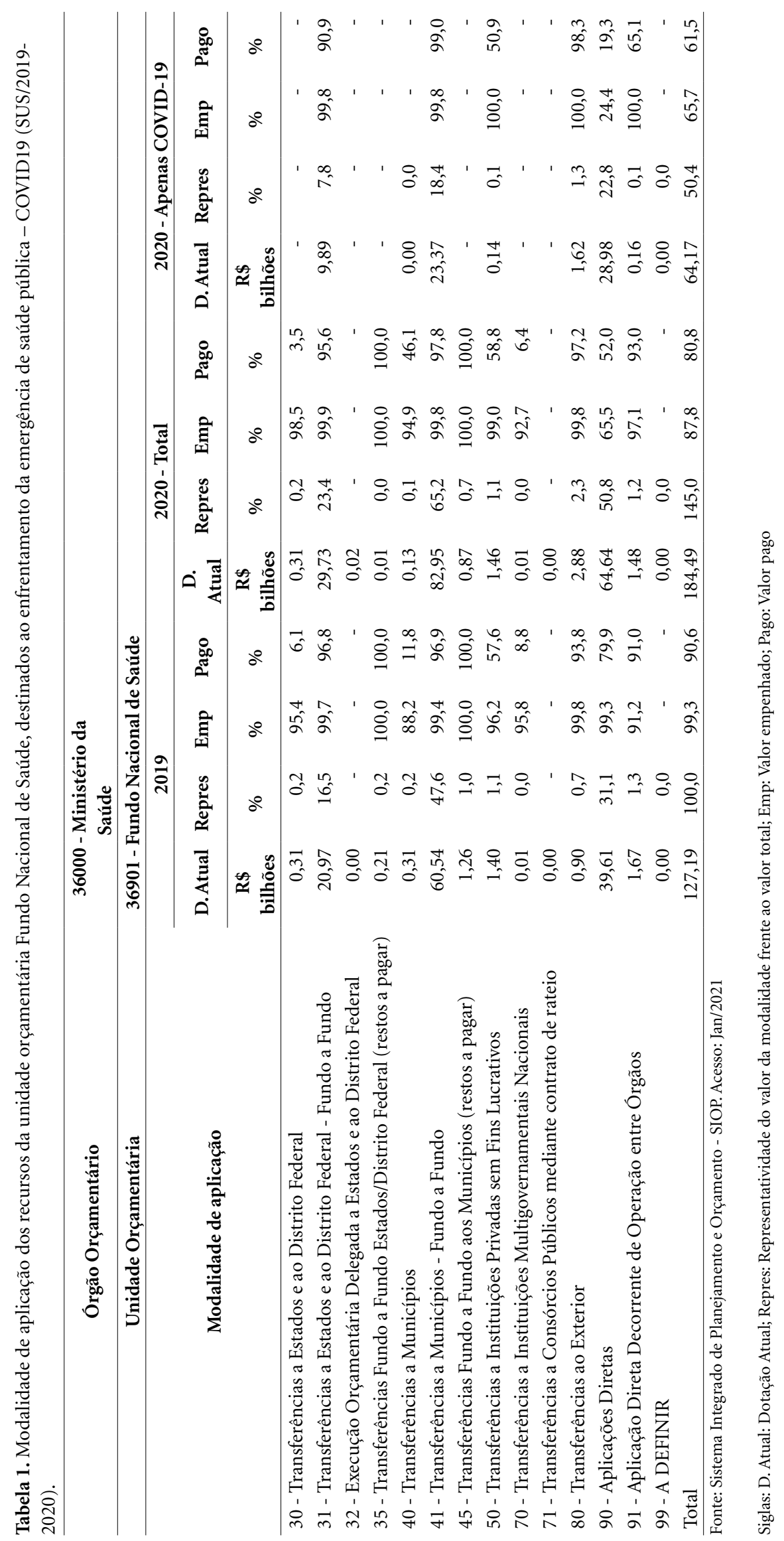




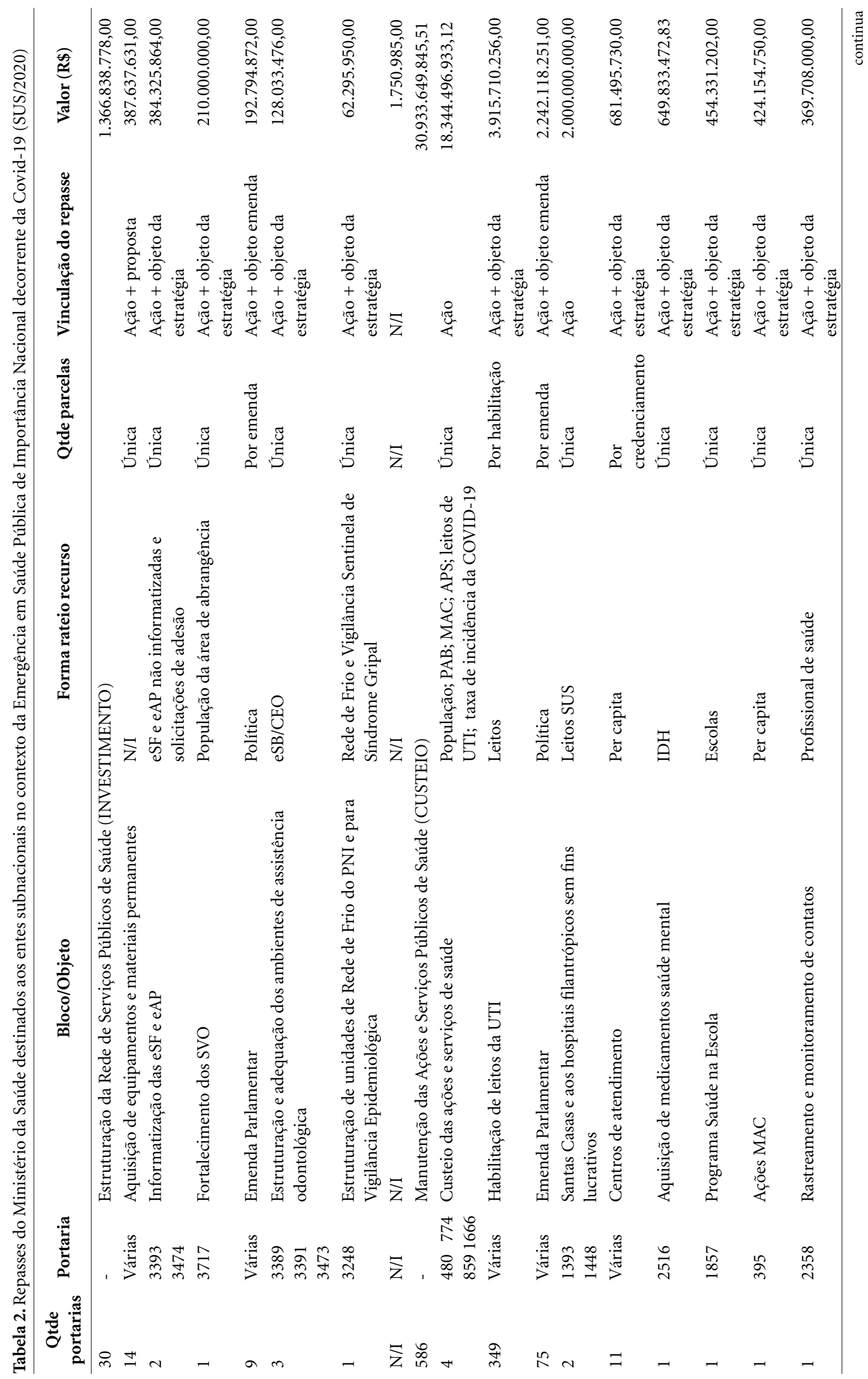




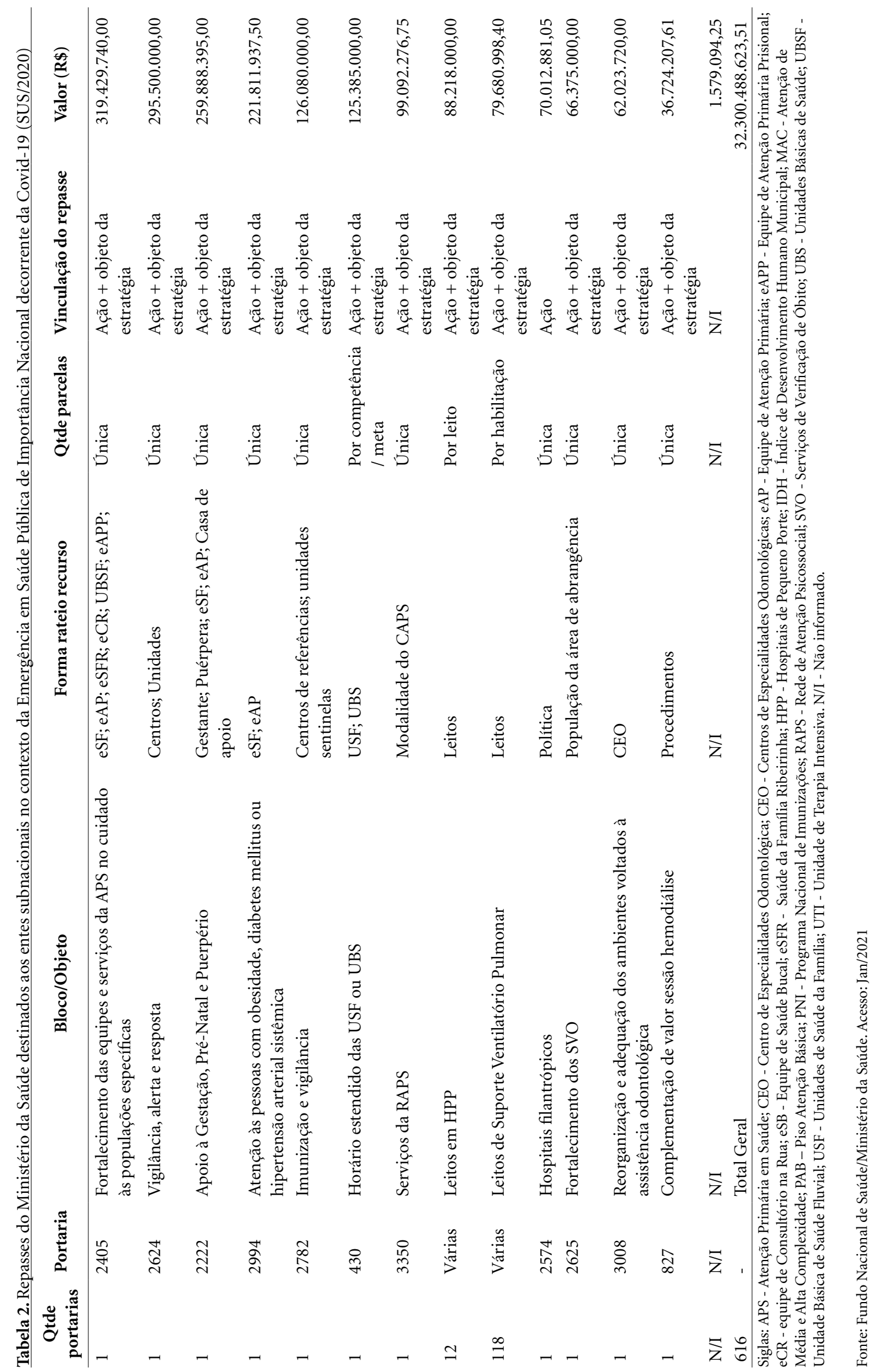


União 21C0 dedicada ao enfrentamento da COVID-19. Ao contrário das demais ações orçamentárias, a 21C0 permeou todas as áreas da saúde, possibilitando que seus recursos fossem executados em ASPS na atenção primária e especializada, vigilância em saúde, assistência farmacêutica, aquisição de suprimentos, insumos e produtos hospitalares. Significa dizer que seria possível que Estados, Distrito Federal e Municípios utilizassem tais recursos, dentro da legalidade, da forma mais célere possível, para atender as demandas locais estabelecidas nos planos regionais de enfrentamento da COVID-19, sem qualquer tipo de engessamento ou vinculação a objetivos específicos de programas, ações, atividades, projetos, operações especiais do MS.

Contudo, registrou-se recorrência da postura do MS (responsável pela maior fatia do financiamento SUS) segundo a qual, mesmo frente a uma emergência internacional de saúde pública, restou mantida a cultura de execução atrelada, não somente a finalidade definida no Programa de Trabalho, mas também aos interesses das áreas finalísticas do MS, limitando a autonomia da gestão e da execução dos recursos recepcionados pelos entes subnacionais ${ }^{16-19}$. Consequentemente, dos $\mathrm{R} \$ 32,30$ bilhões repassados aos entes subnacionais $\mathrm{R} \$ 11,88$ bilhões $(36,8 \%)$ tiveram sua execução engessada, dentre eles: $\mathrm{R} \$ 649,83 \mathrm{mi}-$ lhões (Portaria 2516/20) destinados à aquisição de medicamentos de saúde mental; R $\$ 454,33$ milhões (Portaria 1857/20) para Saúde na Escola; R \$2,24 bilhões (75 Portarias) atrelados a objetos de Emendas Parlamentares.

Sob pena de incorrer em desvio de finalidade, a execução dos recursos pelos entes subnacionais deve observar o cumprimento do objeto e das pactuações disciplinadas nos atos normativos que regulamentaram cada um dos repasses ao tempo da recepção dos recursos no fundo de saúde dos entes subnacionais ${ }^{20}$. De forma prática, caso não tenha sido necessário adquirir medicamentos para a saúde mental ou incrementar os recursos destinados à Saúde na Escola, exclusivamente para enfrentamento da COVID-19, os recursos recepcionados permanecerão eternamente como saldos.

No caso dos recursos extraordinários, o complexo emaranhado normativo do MS contemplou, apenas em 2020, mais de 616 portarias, que em meio a uma pandemia estabeleceram aos gestores de 5.596 fundos subnacionais de saúde aproximadamente trinta diferentes objetivos, mais de 16 formas de cálculo do rateio dos recursos e diversas amarras para a execução des- tes. No Bloco de Estruturação, o que apresenta maior relação com grandes volumes de saldos, 99,9\% dos repasses COVID-19, contabilizando $\mathrm{R} \$ 1,36$ bilhão, tiveram sua execução engessada e no Bloco de Manutenção 34,0\% contabilizando R\$10,52 bilhões.

No que tange execução de recursos ordinários, a situação não é diferente. Os processos orçamentário-financeiros do SUS são disciplinados pela Lei $8.080 / 1990^{21}$, as transferências intergovernamentais de recursos pela Lei no $8.142 / 1990^{22}$, as normas de responsabilidade fiscal pela Lei Complementar no $101 / 2000^{9}$ o orçamento público pela Lei no $4.320 / 1964^{8}$ e o planejamento e a orçamentação do SUS pela Lei Complementar $n^{\circ} 141 / 2012^{5}$. Como se não bastasse, o arcabouço normativo do financiamento e de transferências do SUS foi compilado pela Portaria de Consolidação $n^{\circ} 6 / 2017^{23}$, que ao final de 2020 contabilizava impressionantes 1.171 artigos e 99 anexos. Não há dúvidas de que existem várias origens para o acúmulo de saldos, todavia a produção de inúmeras e complexas normativas internas, que amarram a execução dos recursos para além das finalidades estabelecidas nos programas orçamentários, apresenta-se com uma causa eficiente do empoçamento de recursos no SUS.

Quantidade, qualidade e complexidade normativa se tornaram barreiras à consecução de importantes princípios da administração pública: legalidade e eficiência. Entre os anos de 2014 e 2019, o valor total do empoçamento dos recursos repassados saltou de $\mathrm{R} \$ 5,4$ bilhões ${ }^{24}$ para R\$16,29 bilhões, alcançando em agosto/2020 a incrível cifra de R\$31,74 bilhões. Em 2019, o volume de saldos representou 19,9\% do total de repasses do MS e em 2020 alcançou 21,1\%, com tendência de crescimento.

De maneira geral, os valores de saldos do Bloco de Manutenção, recursos destinados a realizações das ASPS no dia a dia, apresentam maior interesse de análise porque representam 98,0\% do total do volume de repasses. Frente ao total dos valores repassados em 2019, estes representam para $58 \%$ dos municípios o montante recebido em 2,4 meses e para 56\% dos estados 2,7 meses. Há indícios, verificados em consultas individuais ao portal eletrônico do FNS, de que alguns municípios recebam, em contas-correntes que já deveriam ter sido encerradas, depósitos não provenientes do FNS. Acredita-se que tais créditos sejam provenientes dos Estados, todavia, faz-se necessária investigação para se conhecer a origem, o volume e o quanto representam no total do empoçamento. 
Por sua vez, os valores transferidos por meio do Bloco de Estruturação se referem a repasses de capital, cuja execução demanda processos administrativos específicos, muitas vezes dificultados por entraves como em decorrência de processos de licitação, ou correlatos, seja pela não entrega de bens ou serviços contratados, seja por problemas técnicos, ambientais, ou o não recebimentos dos recursos pactuados, seja ainda por processos judiciais ou dos órgãos de controle ${ }^{25}$.

Não há dúvida de que em 2020 parte do aumento dos saldos é proveniente dos recursos extraordinários para o enfrentamento da COVID-19. Uma das causas do empoçamento foi a pouca celeridade dos repasses, o que proporcionou grandes volumes nos meses de junho $(20 \%)$ e agosto (28\%). Todavia, uma causa estrutural diz respeito a entraves estabelecidos por normas que vincularam $34 \%$ da execução dos recursos a estratégias e programas do MS, muito além da vinculação legal de finalidade, definida no Programa de Trabalho do Orçamento, prática comum no SUS também para os recursos ordinários.

No início da pandemia foi promulgada a Lei Complementar $n^{\circ} 172 / 2020^{14}$ objetivando viabilizar a execução dos saldos remanescentes. Assim, diante do cumprimento dos respectivos objetos pactuados, da inclusão dos recursos na Programação Anual de Saúde e na Lei Orçamentária Anual local e dando ciência das modificações aos respectivos Conselhos de Saúde, foi possibilitado aos gestores subnacionais redirecionar os recursos remanescentes, destinando-os a execução das ASPS estabelecidas em seus planos locais de saúde. No entanto, o mecanismo possibilitou alterações somente a vigência da Decreto Legislativo $n^{\circ} 6 / 2020^{26}$, diferentemente do que previa o projeto original: a repriorização ao final de cada exercício financeiro $^{27}$. A fim de viabilizar a execução de dezenas de bilhões de reais destinados à COVID-19, ao final de 2020 o Decreto Presidencial $\mathrm{n}^{\circ} 10.579 / 2020^{28}$ e posteriormente a Lei Complementar $n^{\circ} 181 / 21^{29}$ estabeleceram que os entes subnacionais poderão executar tais recursos até dezembro/2021.

A autorização legislativa por tempo limitado é apropriada, mas não resolve o problema. Neste estudo chama atenção o fato do MS estabelecer, em plena pandemia, mais de 16 formas de cálculo para o rateio dos recursos. Se houvesse no SUS uma metodologia de rateio estabelecida e amplamente utilizada, bem como um processo de planejamento e orçamento ascendente, ambos baseados nas necessidades de saúde da população, considerando as dimensões epidemiológica, demográfica, socioeconômica, espacial e de capacidade de oferta das ações e dos serviços de saúde ${ }^{5}$, todo o processo orçamentário seria muito mais eficaz.

Neste sentido, merece destaque o entendimento da Subsecretaria de Planejamento e Orçamento (SPO) da Secretaria Executiva do MS, segundo o qual todos os repasses realizados aos entes subnacionais na modalidade fundo a fundo poderiam ocorrer por meio de no máximo 16 programações orçamentárias para cada bloco de financiamento ${ }^{30,31}$. Este estudo tem como limitações as inerentes bases de dados do SUS e o fato de que $0,01 \%$ dos valores dos repasses não registrarem informações capazes de classificá-los. Uma outra limitação diz respeito a não realização de uma análise sobre a execução, pelos entes subnacionais, dos recursos repassados. Todavia, em função do volume de dados e informações, derivado de um tema naturalmente complexo, os autores decidiram por tornar tal limitação mote de novos estudos.

\section{Conclusão}

Várias podem ser as causas que originam o acúmulo de saldos, mas sem dúvida a qualidade, a quantidade e a complexidade do arcabouço normativo do SUS contribuem fortemente para o empoçamento dos recursos. Se os repasses financeiros federais fundo a fundo ocorressem segundo critérios de rateios previamente estabelecidos, já determinado por Lei, e por meio de no máximo das 16 programações orçamentárias, já definidas pelo MS, indubitavelmente a execução dos recursos recepcionados pelos entes subnacionais seria mais abrangente, célere, efetiva, eficiente e eficaz, com maior adesão ao atendimento às demandas locais e com níveis de empoçamento muito inferiores aos atuais. 


\section{Colaboradores}

DR Faleiros e BLS Pereira responderam pelo: desenho e governança do estudo; redação e revisão crítica contínua do artigo; materiais / ferramentas de análise; revisão do estudo em andamento e feedback sobre o desenho, coleta de dados, análise e revisão crítica do manuscrito. Todos os autores tiveram acesso total a todos os dados e assumem a responsabilidade pela integridade dos dados e pela precisão da análise dos dados.

\section{Referências}

1. Brasil. Congresso Nacional. Constituição da República Federativa do Brasil. Brasília, DF: Centro Gráfico, 1988. [acessado 2020 maio 30]. Disponível em: http:// www.planalto.gov.br/ccivil_03/constituicao/constituicaocompilado.htm

2. Nunes A. A alocação equitativa inter-regional de recursos públicos federais do SUS: a receita própria do município como variável moderadora. Relatório de Consultoria. Consolidação do Sistema de Informações sobre Orçamentos Públicos em Saúde - SIOPS. Brasília, DF: Ministério da Saúde; 2004 [acessado 2020 out 30]. Disponível em: http://siops.datasus.gov.br/Documentacao/Aloc_Equitativa_SIOPS.pdf

3. Dain S. Os vários mundos do financiamento da Saúde no Brasil: uma tentativa de integração. Cien Saude Colet 2007; 12(Supl.):1851-1864.

4. Brasil. Congresso Nacional. Emenda Constitucional $n^{\circ}$ 29, de 13 de setembro de 2000. Altera os arts. 34, 35, 156, 160, 167 e 198 da Constituição Federal e acrescenta artigo ao Ato das Disposições Constitucionais Transitórias, para assegurar os recursos mínimos para o financiamento das ações e serviços públicos de saúde. Brasília, DF [acessado 2020 out 30]. Disponível em: http://www.planalto.gov.br/ccivil_03/constituicao/Emendas/Emc/emc29.htm

5. Brasil. Congresso Nacional. Lei Complementar № 141 , de 13 de janeiro de 2012. Regulamenta o $\$ 3^{\circ}$ do art. 198 da Constituição Federal para dispor sobre os valores mínimos a serem aplicados anualmente pela União, Estados, Distrito Federal e Municípios em ações e serviços públicos de saúde; estabelece os critérios de rateio dos recursos de transferências para a saúde e as normas de fiscalização, avaliação e controle das despesas com saúde nas três esferas de governo; revoga dispositivos das Leis nos 8.080, de 19 de setembro de 1990, e 8.689, de 27 de julho de 1993; e dá outras providências. Diário Oficial da União. Brasília, DF; 2012 [acessado 2020 out 30]. Disponível em: http://www.planalto.gov.br/ccivil_03/leis/LCP/Lcp 141.htm

6. Brasil. Conselho Nacional de Secretários de Saúde (CONASS). A Lei no 141/2012 e os Fundos de Saúde / Conselho Nacional de Secretários de Saúde. Brasília: CONASS; 2013. 159 p. (CONASS Documenta, 26) [acessado 2020 out 30]. Disponível em: https://www. conass.org.br/conassdocumenta/conassdocumenta_26.pdf

7. Brasil. Ministério da Saúde (MS). Sistema de Informação sobre Orçamento Público em Saúde - SIOPS. [Internet] Brasília: MS; 2020 [acessado 2020 out 30]. Disponível em: http://siops.datasus.gov.br/

8. Brasil. Presidência da República. Casa Civil. Subchefia para Assuntos Jurídicos. Lei no 4.320, de 17 de março de 1964. Estatui normas gerais de direito financeiro para elaboração e controle dos orçamentos e balanços da União, dos Estados, dos Municípios e do Distrito Federal. Diário Oficial da União. Brasília, DF; 1964 [acessado 2020 out 30]. Disponível em: http://www. planalto.gov.br/ccivil_03/leis/14320.htm 
9. Brasil. Presidência da República. Lei Complementar $\mathrm{n}^{\circ}$ 101, de 4 de maio de 2000. Estabelece normas de finanças públicas voltadas para a responsabilidade na gestão fiscal e dá outras providências. Diário Oficial da União. Brasília, DF; 2000 [acessado 2021 jun 29]. Disponível em: http://www.planalto.gov.br/ccivil_03/ leis/lcp/lcp101.htm

10. Brasil. Ministério da Saúde (MS). Fundo Nacional de Saúde (FNS). [Internet] Brasília: MS; 2020 [acessado 2021 jan 10]. Disponível em: https://portalfns.saude. gov.br/

11. Fernandes A, Tomazelli I. Rombo do setor público virá abaixo do esperado e não deve passar de R $\$ 120$ bi. $O$ Estado de S.Paulo. São Paulo, 04 de outubro de 2018 | 04h00. Economia. [acessado 2021 jun 28]. Disponível em: https://economia.estadao.com.br/noticias/geral, rombo-do-setor-publico-vira-abaixo-do-esperado-enao-deve-passar-de-r-120-bi,70002531804

12. Brasil. Ministério da Economia. Sistema Integrado de Planejamento e Orçamento - SIOP. [Internet] Brasília: Ministério da Economia; 2020 [acessado 2020 out 30]. Disponível em: https://www.siop.planejamento. gov.br/

13. Brasil. Congresso Nacional. Decreto Legislativo $n^{\circ}$ 6/2020. (2020). Reconhece, para os fins do art. 65 da Lei Complementar no 101, de 4 de maio de 2000, a ocorrência do estado de calamidade pública, nos termos da solicitação do Presidente da República encaminhada por meio da Mensagem no 93, de 18 de março de 2020. Diário Oficial da União. Brasília, DF; 2020 [acessado 2020 ago 4]. Disponível em: http://www. planalto.gov.br/ccivil_03/portaria/DLG6-2020.htm

14. Brasil. Congresso Nacional. Lei Complementar $n^{\circ}$ 172, de 15 de abril de 2020. (2020). Dispõe sobre a transposição e a transferência de saldos financeiros constantes dos Fundos de Saúde dos Estados, do Distrito Federal e dos Municípios, provenientes de repasses federais. Diário Oficial da União. Brasília, DF; 2020 [acessado 2020 out 30]. Disponível em: http://www. planalto.gov.br/ccivil_03/leis/lcp/lcp172.htm

15. Brasil. Ministério da Saúde (MS). Portal Localiza SUS - Painel de Saldos. [Internet] Brasília: MS; 2020 [acessado 2021 jan 10]. Disponível em: https://localizasus. saude.gov.br/

16. Fernandes GAAL, Pereira BLS. Os desafios do financiamento da ação de enfrentamento ao COVID-19 no SUS dentro do pacto federativo. Rev Administração Pública 2020; 54(4):595-613.

17. Duarte LS, Mendes AN, Louvison MCP. O processo de regionalização do SUS e a autonomia municipal no uso dos recursos financeiros: uma análise do estado de São Paulo (2009-2014). Saude Debate 2018; 42(116):25-37.

18. Vazquez DA. Efeitos da regulação federal sobre o financiamento da saúde. Cad Saude Publica; 27(6):1201-1212

19. Harzheim E, D'Avila OP, Ribeiro DC, Ramos LG, Silva LE, Santos CMJ, Costa LGM Cunha CRH, Pedebos LA. Novo financiamento para uma nova Atenção Primária à Saúde no Brasil. Cien Saude Colet 2020; 25(4):1361-1374.
20. Brasil. Ministério da Saúde (MS). Portaria No 3.992, de 28 de dezembro de 2017. Altera a Portaria de Consolidação no 6/GM/MS, de 28 de setembro de 2017, para dispor sobre o financiamento e a transferência dos recursos federais para as ações e os serviços públicos de saúde do Sistema Único de Saúde. Brasília: MS; 2017 [acessado 2020 out 20]. Disponível em: https://bvsms.saude.gov.br/bvs/saudelegis/gm/2017/ prt3992_28_12_2017.html

21. Brasil. Presidência da República. Lei no 8.080, de 19 de setembro de 1990. (1990). Dispõe sobre as condições para a promoção, proteção e recuperação da saúde, a organização e o funcionamento dos serviços correspondentes e dá outras providências. Diário Oficial da União. Brasília, DF; 1/0]. Disponível em: http://www. planalto.gov.br/ccivil_03/leis/L8080.htm

22. Brasil. Presidência da República. Lei no 8.142 , de 28 de dezembro de 1990. (1990). Dispõe sobre a participação da comunidade na gestão do Sistema Único de Saúde (SUS) e sobre as transferências intergovernamentais de recursos financeiros na área da saúde e dá outras providências. Diário Oficial da União. Brasília, DF; 1990 [acessado 2020 out 30]. Disponível em: http://www.planalto.gov.br/ccivil_03/leis/18142.htm

23. Brasil. Ministério da Saúde (MS). Gabinete do Ministro. Portaria de Consolidação no 6 , de 28 de setembro de 2017. Consolidação das normas sobre o financiamento e a transferência dos recursos federais para as ações e os serviços de saúde do Sistema Único de Saúde. Diário Oficial da União. Brasília: MS; 2007 [acessado 2020 ago 30]. Disponível em: http://bvsms.saude.gov.br/bvs/saudelegis/gm/2017/ prc0006_03_10_2017.html

24. Pereira BLS, Oliveira Jr. ACR, Faleiros DR. Portaria 3992/2017: desafios e avanços para gestão dos recursos no Sistema Único de Saúde. Rev Saude Publica 2019; 53:58.

25. Brasil. Tribunal de Contas da União (2019). Auditoria Operacional sobre Obras Paralisadas. Acórdão: 1.079/2019 - TCU - Plenário Data de sessão: 15/5/2019 Relator: Ministro Vital do Rêgo TC: 011.196/2018-1 Unidade Técnica Responsável: Seinfra Urbana. Brasília. 2019 [acessado 2020 out 30]. Disponível em: https://portal.tcu.gov.br/bibliotecadigital/auditoria-operacional-sobre-obras-paralisadas.htm

26. Brasil. Congresso Nacional. Decreto Legislativo $\mathrm{n}^{\circ}$ 6/2020. (2020). Reconhece, para os fins do art. 65 da Lei Complementar $n^{\circ} 101$, de 4 de maio de 2000, a ocorrência do estado de calamidade pública, nos termos da solicitação do Presidente da República encaminhada por meio da Mensagem no 93, de 18 de março de 2020. Diário Oficial da União. Brasília, DF; 2020 [acessado 2020 ago 4]. Disponível em: http://www. planalto.gov.br/ccivil_03/portaria/DLG6-2020.htm

27. Brasil. Câmara dos Deputados. Projeto de Lei Complementar $n^{\circ}$ 232/2019 (2019).- PLP 232/2019. Câmara dos Deputados. 2020 [acessado 2020 out 30]. Disponível em: https://www.camara.leg.br/proposicoesWeb/ prop_mostrarintegra;jsessionid=411E238328054EDDE64D406E2FEFEDF4.proposicoesWebExterno1?codteor $=1817768 \&$ filename $=\mathrm{PLP}+232 / 2019$ 
28. Brasil. Presidência da República. Secretaria-Geral. Subchefia para Assuntos Jurídicos. Decreto no 10.579, de 18 de dezembro de 2020. Estabelece regras para a inscrição de restos a pagar das despesas de que trata o art. $5^{\circ}$ da Emenda Constitucional no 106 , de 7 de maio de 2020, e dá outras providências. Diário Oficial da União. Brasília, DF; 2020 [acesso 20 dezembro 2020]. Disponível em: http://www.planalto.gov.br/ ccivil_03/_Ato2019-2022/2020/Decreto/D10579.ht-

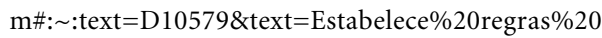
para $\% 20$ a $\% 20$ inscri $\%$ C3\%A7\%C3\%A3o,que $\% 20$ lhe $\% 20$ confere $\% 200 \% 20$ art

29. Brasil. Congresso Nacional. Lei Complementar $n^{\circ}$ 181, de 6 de maio de 2021. (2021). Altera a Lei Complementar $\mathrm{n}^{\circ} 172$, de 15 de abril de 2020 , e a Lei ${ }^{\circ}$ 14.029, de 28 de julho de 2020, para conceder prazo para que os Estados, o Distrito Federal e os Municípios executem atos de transposição e de transferência e atos de transposição e de reprogramação, respectivamente; (...). Diário Oficial da União. Brasília, DF; 2021 [acessado 2021 jun 21]. Disponível em: https://www. in.gov.br/en/web/dou/-/lei-complementar-n-181-de6-de-maio-de-2021-318445559

30. Brasil. Ministério da Saúde (MS). Secretaria Executiva/Subsecretaria de Planejamento e Orçamento. Por$\operatorname{taria}^{\circ} 1$, de 17 de janeiro de 2019. Divulga a relação das programações orçamentárias oneradas por transferências de recursos, na modalidade fundo a fundo, do Fundo Nacional de Saúde aos Fundos de Saúde Estaduais, Municipais e do Distrito Federal, bem como a vinculação desses programas de trabalho com os blocos de financiamento de que trata a Portaria de Consolidação no 6/GM/MS, de 28 de setembro de 2017. Diário Oficial da União. Brasília: MS; 2019 [acessado 2020 out 6]. Disponível em: https://www.in.gov.br/ materia/-/asset_publisher/Kujrw0TZC2Mb/content/ $\mathrm{id} / 59814383$

31. Brasil. Ministério da Saúde (MS). Secretaria Executiva/Subsecretaria de Planejamento e Orçamento. Portaria $n^{\circ}$ 2, de 24 de janeiro de 2020. (2020). Divulga a relação das programações orçamentárias oneradas por transferências de recursos, na modalidade fundo a fundo, do Fundo Nacional de Saúde aos Fundos de Saúde Estaduais, Municipais e do Distrito Federal, bem como a vinculação desses programas de trabalho com os blocos de financiamento de que trata a Portaria de Consolidação n ${ }^{\circ}$ 6/GM/MS, de 28 de setembro de 2017. Diário Oficial da União. Brasília, DF; 2019 [acesso 06 outubro 2020]. Disponível em: https:// www.in.gov.br/web/dou/-/portaria-n-2-de-24-de-janeiro-de-2020-240565680

Artigo apresentado em 23/03/2021

Aprovado em 16/08/2021

Versão final apresentada em 18/08/2021

Editores-chefes: Romeu Gomes, Antônio Augusto Moura da Silva 
